\title{
Behaviour of large-scale columns confined with FRP composites in compression
}

\author{
H. Toutanji \\ Department of Civil and Environmental Engineering, University of Alabama in Huntsville, Huntsville, AL \\ 35899, USA
}

S. Matthys, L. Taerwe \& K. Audenaert

Magnel Laboratory for Concrete Research, Ghent University, Technologiepark-Zwijnaarde 904, B-9052 Gent, Belgium

\begin{abstract}
The behaviour of fiber reinforced polymer (FRP)-confined concrete has been extensively studied. Most of the existing models have been concerned with small-size cylinders. This paper presents the experimental and analytical results of axially loaded large-scale columns confined with FRP wrapping reinforcement. The effective circumferential FRP failure strain and the effect of increasing confining action were investigated. The reliability of different models for the prediction of the ultimate strength of FRP-confined concrete has been verified when applied to real scale axially loaded columns. A revision of an existing model developed earlier by the first author was presented. The revised model addresses the effective FRP failure strain that is attributed to localized stress concentrations near failure due to non-homogenous deformations of the damaged concrete. A comparison between the experimental results and those predicted by the existing models was investigated. Based on the model verification, results show that only few of these models seem to predict the behaviour of the tested large-scale columns accurately.
\end{abstract}

\section{INRODUCTION}

Concrete columns have an important function in the structural concept of many structures. Often, these columns are vulnerable to exceptional loads (such as impact, explosion or seismic loads), load increase (increasing use or change of function of structures, etc.) and degradation (corrosion of steel reinforcement, alkali silica reaction, etc.). On the other hand, confinement of concrete is an efficient technique to increase the load carrying capacity and ductility of concrete members primarily subjected to compression. By providing lateral confining pressure, the concrete is subjected to a tri-axial state of stress, so that the compressive strength and deformability increase. Since the introduction of FRP as externally bonded reinforcement, confinement by means of FRP wrapping has been of considerable interest for upgrading columns, piers, chimneys, etc. and several research programs have been conducted internationally.

To verify the effectiveness of FRP confinement with respect to real-scale axially loaded columns and to investigate some specific aspects of the modeling of FRP confined concrete, compression tests on large-scale columns wrapped with FRP have been performed (Matthys 2000). The variables considered in this test program included FRP type, full or partial wrapping, and fibre orientation (circular or helicoidal). This research mainly focuses on the experi- mental and analytical work concerning large-scale axially loaded columns, confined with external FRP wrapping reinforcement. The study also looks into the strength modeling of FRP confined concrete, i.e. the effective circumferential FRP failure strain and the effect of increasing confining action.

\section{EXPERIMENTAL PROCEDURE}

Eight large-scale columns were manufactured. The confined-concrete columns were subjected to axial loading. The test parameters of the wrapped columns are given in Table $1 \mathrm{a}, \mathrm{b}$. The columns had a total length of $2 \mathrm{~m}$, a longitudinal steel reinforcement ratio of $0.9 \%$ and $8 \mathrm{~mm}$ diameter stirrups spaced every $140 \mathrm{~mm}$. Extra stirrup reinforcement was provided at the column ends. All columns have a $400 \mathrm{~mm}$ circular cross-section. Except for columns K6 and K7, the FRP is applied over the total area (full wrapping) in a circular way, providing $200 \mathrm{~mm}$ overlap length in the circumferential direction (no overlap was provided in the longitudinal direction). For columns K6 and $\mathrm{K} 7$ partial wrapping is applied, either in a circular way with a clear spacing of $200 \mathrm{~mm}$ (K6) or in a helicoidal way with a pitch of $400 \mathrm{~mm}$ and a clear spacing of $200 \mathrm{~mm}$ (K7). 
Table 1a. Test parameters of wrapped columns.

\begin{tabular}{l|l|l|l}
\hline \multirow{2}{*}{ Spec. } & \multirow{2}{*}{ Column diameter } & \multicolumn{3}{l}{ Concrete } & \\
\cline { 3 - 4 } & & Age at test & $f^{\prime}{ }^{\prime}(28$ days $)$ \\
\hline $\mathrm{K} 1$ & $\varnothing 400$ & {$[$ days $]$} & {$\left[\mathrm{N} / \mathrm{mm}^{2}\right]^{(1)}$} \\
\hline $\mathrm{K} 2$ & $\varnothing 400$ & 29 & 31.8 \\
\hline $\mathrm{K} 3$ & $\varnothing 400$ & 28 & 34.3 \\
\hline $\mathrm{K} 4$ & $\varnothing 400$ & 29 & 34.3 \\
\hline $\mathrm{K} 5$ & $\varnothing 400$ & 29 & 39.3 \\
\hline $\mathrm{K} 6$ & $\varnothing 400$ & 32 & 39.3 \\
\hline $\mathrm{K} 7$ & $\varnothing 400$ & 28 & 35.8 \\
\hline $\mathrm{K} 8$ & $\varnothing 400$ & 28 & 35.8 \\
\hline
\end{tabular}

${ }^{\text {(1) }} \mathrm{N} / \mathrm{mm}^{2}=\mathrm{MPa}$

Table 1b. Test parameters of wrapped columns.

\begin{tabular}{l|l|l|l|l|l|l}
\hline \multirow{2}{*}{ Spec. } & \multicolumn{6}{l}{ FRP Confinement } \\
\cline { 2 - 7 } & FRP type & $\begin{array}{l}\text { No. of } \\
\text { layers }\end{array}$ & Width & $\begin{array}{l}\text { Clear } \\
\text { spacing }\end{array}$ & Pitch & Wrapping \\
\hline K1 & - & - & - & - & - & - \\
\hline K2 & C240 & 5 & 300 & 0 & 0 & full \\
\hline K3 & C640 & 4 & 300 & 0 & 0 & full \\
\hline K4 & TU600/25 & 6 & 200 & 0 & 0 & full \\
\hline K5 & TU600/25 & 2 & 200 & 0 & 0 & full \\
\hline K6 & TU600/25 & 4 & 200 & 200 & 0 & partial \\
\hline K7 & TU600/25 & 4 & 200 & 200 & 400 & partial \\
\hline K8 & $\begin{array}{l}\text { TU360G160 } \\
\text { C/27G }\end{array}$ & 4 & 50 & 0 & 0 & full \\
\hline
\end{tabular}

Different types of FRP reinforcement consisting of CFRP sheets (C240 and C640), GFRP fabrics (TU600/25) and HFRP (hybrid FRP) fabric (TU360G160C/27G) have been used to confine the concrete columns. Tensile tests (according to ASTM D3039/D3039M) were performed on FRP sheet specimens with a width of 50 or $100 \mathrm{~mm}$. Results of the tensile tests of the FRP sheets and the longitudinal steel rebars and stirrups are reported in terms of mean values in Table $2 a, b$.

The concrete columns were subjected to an axial load test in a compression testing machine with a capacity of $10000 \mathrm{kN}$. The load was applied in a displacement controlled mode at $0.5 \mathrm{~mm} / \mathrm{min}$. Due to problems with the loading control unit, the displacement rate of column $\mathrm{K} 2$ decreased after reaching maximum load. Axial and circumferential deformations of the columns were measured both manually and electronically. Manual measurements comprised dial gauges with a gauge length of $1 \mathrm{~m}$ and mechanical deformeters with a gauge length of $200 \mathrm{~mm}$ or $50 \mathrm{~mm}$. For the electronic measurements, both strain stirrups (gauge length $200 \mathrm{~mm}$ or 80 $\mathrm{mm}$ ) and strain gauges have been used.

Table 2a. Mean tensile properties obtained by tensile testing.

\begin{tabular}{|c|c|c|}
\hline Type & $\begin{array}{l}\text { Nominal } \\
\text { Dimensions }\end{array}$ & $\begin{array}{l}\text { Yield } \\
\text { strength }\end{array}$ \\
\hline & $(\mathrm{mm})$ & $\left(\mathrm{N} / \mathrm{mm}^{2}\right)$ \\
\hline Steel Rebar S500 ${ }^{(1)}$ & $\begin{array}{ll}\varnothing & 8 \\
\varnothing & 12\end{array}$ & $\begin{array}{l}560 \\
620\end{array}$ \\
\hline C-sheet 240 - Multipox T & $300 \times 0.117^{(2)}$ & - \\
\hline C-sheet 640 - Multipox T & $300 \times 0.235^{(2)}$ & - \\
\hline TU600/25 - PC5800 & $200 \times 0.300^{(2)}$ & - \\
\hline $\begin{array}{l}\text { TU360G160C/27G- } \\
\text { PC5800 }\end{array}$ & $50 \times 0.123^{(2)}$ & - \\
\hline
\end{tabular}

(1) Characteristic yield strength value equal to $500 \mathrm{~N} / \mathrm{mm}^{2}$

${ }^{(2)}$ Equivalent dry-fibre thickness

Table $2 \mathrm{~b}$. Mean tensile properties obtained by tensile testing.

\begin{tabular}{l|l|l|l}
\hline Type & $\begin{array}{l}\text { Tensile } \\
\text { Strength }\end{array}$ & $\begin{array}{l}\text { Ultimate } \\
\text { strain }\end{array}$ & $\begin{array}{l}\text { E- } \\
\text { modulus }\end{array}$ \\
\hline & $\left(\mathrm{N} / \mathrm{mm}^{2}\right)$ & $(\%)$ & $\left(\mathrm{N} / \mathrm{mm}^{2}\right)$ \\
\hline Steel Rebar S500 & 610 & 2.77 & 200000 \\
& 720 & 8.73 & 200000 \\
\hline C-sheet 240 - Multipox T & 2600 & 1.19 & 198000 \\
\hline C-sheet 640 - Multipox T & 1100 & 0.22 & 480000 \\
\hline TU600/25 - PC5800 & 780 & 1.30 & 60000 \\
\hline $\begin{array}{l}\text { TU360G160C/27G- } \\
\text { PC5800 }\end{array}$ & 1100 & 0.96 & 120000 \\
\hline
\end{tabular}

\section{EXPERIMENTAL TEST RESULTS}

\subsection{Behaviour at ultimate load}

The test results of the columns in terms of maximum load $\mathrm{Q}_{\max }$, axial stress (maximum load $\mathrm{Q}_{\max } /$ gross column section $\left.\mathrm{A}_{\mathrm{g}}\right)$, strength increase, axial $\left(\varepsilon_{\mathrm{c} 1}\right.$ and $\left.\varepsilon_{\mathrm{cu}}\right)$ and circumferential strains $\left(\varepsilon_{c \ell 1}\right.$ and $\left.\varepsilon_{c \ell u}\right)$ at maximum and ultimate load respectively and ratio of the circumferential strain $\varepsilon_{\mathrm{c} \ell \mathrm{u}}$ over the FRP failure strain $\varepsilon_{\mathrm{fu}}$ are given in Table $3 \mathrm{a}, \mathrm{b}$. The mentioned strains are the mean values of the strain gauge measurements.

Table 3a. Test results of compression tests on columns.

\begin{tabular}{l|l|l|l}
\hline \multirow{2}{*}{ Specimen } & $\mathrm{Q}_{\max }$ & $\mathrm{Q}_{\max } / \mathrm{A}_{\mathrm{g}}$ & $\mathrm{Q} / \mathrm{Q}_{\text {ref }}$ \\
\cline { 2 - 4 } & {$[\mathrm{kN}]$} & {$\left[\mathrm{N} / \mathrm{mm}^{2}\right]$} & {$[-]$} \\
\hline K1 (Ø/Ref. & 4685 & 37.3 & 1.00 \\
\hline $\mathrm{K} 2(\varnothing / \mathrm{C} 240 / \# 5 /$ full $)$ & 7460 & 59.4 & 1.59 \\
\hline $\mathrm{K} 3(\varnothing / \mathrm{C} 640 / \# 4 /$ full $)$ & 7490 & 59.6 & 1.60 \\
\hline $\mathrm{K} 4(\varnothing / \mathrm{G} / \# 6 /$ full $)$ & 7580 & 60.3 & 1.62 \\
\hline K5 (Ø/G/\#2/full) & 5325 & 42.4 & 1.14 \\
\hline K6 (Ø/G/\#4/partial-circ. $)$ & 5000 & 39.8 & 1.07 \\
\hline K7 (Ø/G/\#4/partial-helic. $)$ & 4810 & 38.3 & 1.03 \\
\hline K8 (Ø/H/\#4/full) & 6230 & 49.6 & 1.33 \\
\hline
\end{tabular}


Table 3b. Test results of compression tests on columns.

\begin{tabular}{|c|c|c|c|c|c|}
\hline \multirow{2}{*}{ Specimen } & & $\varepsilon_{\mathrm{cu}}$ & $\varepsilon_{c / 1}$ & $\varepsilon_{c / u}$ & $\varepsilon_{c / u} / \varepsilon_{\mathrm{fu}}$ \\
\hline & {$[\mathrm{mm} / \mathrm{m}]$} & {$[\mathrm{mm} / \mathrm{m}]$} & {$[\mathrm{mm} / \mathrm{m}]$} & {$[\mathrm{mm} / \mathrm{m}]$} & {$[-]$} \\
\hline K1 (Ø/Ref.) & 2.8 & $3.1^{(1)}$ & 1.7 & $1.8^{(1)}$ & - \\
\hline $\begin{array}{l}\mathrm{K} 2 \\
(\varnothing / \mathrm{C} 240 / \# 5 / \text { full })\end{array}$ & 11.1 & $(12.0)^{(2)}$ & 6.9 & $(7.3)^{(2)}$ & $(0.61)^{(2)}$ \\
\hline $\begin{array}{l}\text { K3 } \\
(\emptyset / C 640 / \# 4 / \text { full })\end{array}$ & 4.3 & 4.3 & 2.5 & 2.5 & 1.14 \\
\hline K4 (Ø/G/\#6/full) & 6.9 & 6.9 & 7.5 & 7.5 & 0.58 \\
\hline K5 (Ø/G/\#2/full) & 3.8 & 3.8 & 6.8 & 8.0 & 0.62 \\
\hline $\begin{array}{l}\mathrm{K} 6 \\
(\emptyset / \mathrm{G} / \# 4 / \text { partial- } \\
\text { circ.) } \\
\end{array}$ & 2.8 & 3.3 & 1.6 & 3.3 & 0.25 \\
\hline $\begin{array}{l}\mathrm{K} 7 \\
\text { (Ø/G/\#4/partial- } \\
\text { helic.) }\end{array}$ & 2.2 & 2.2 & 3.1 & 3.3 & 0.25 \\
\hline K8 (Ø/H/\#4/full) & 5.9 & 6.0 & 5.3 & 5.3 & 0.55 \\
\hline
\end{tabular}

(1) Test stopped at an axial strain of about $3.1 \mathrm{~mm} / \mathrm{m}$.

(2) Problems with the load control unit of the actuator in the post peak region.

The unconfined ultimate compressive strength of the control column (K1) was $37.3 \mathrm{MPa}$. A strength increase up to 1.62 is found for the different columns and strongly depends on the wrapping lay-out, and FRP type and amount. The confined concrete columns failed by fracture of the FRP reinforcement, as shown in Figure 1. For the fully wrapped circular columns at ultimate load, when confinement action was no longer provided due to FRP fracture, the internal steel started buckling and the crushed concrete fell down between the fractured FRP. For the partially wrapped columns it was noted that the unconfined zones started crushing when reaching the strength of the plain concrete. For these columns, buckling of the internal steel occurred in the unconfined zones, after FRP failure.

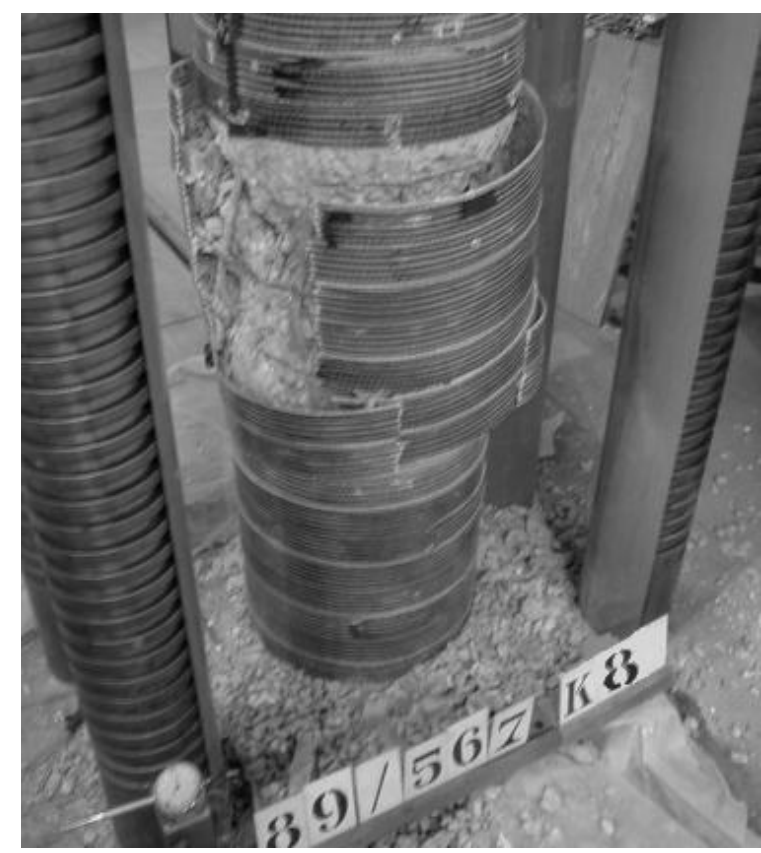

Figure 1a. Failure of HFRP fully wrapped column.

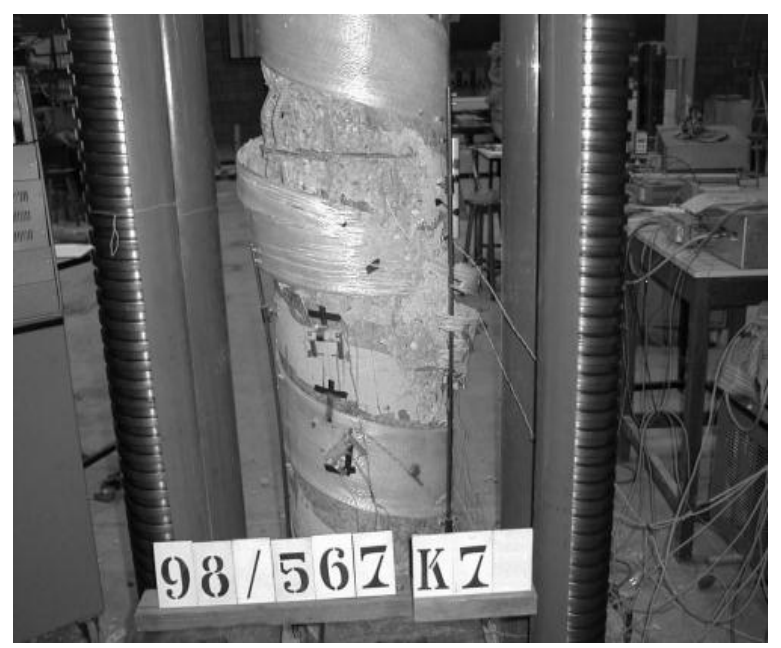

Figure 1b. Failure of GFRP partially wrapped column.

Figure 1. Failure aspect of the confined columns.

Results show that the strength increase basically depends on the amount and tensile strength of the FRP wrapping. The higher the axial stiffness of the FRP wrapping, the lower the ultimate axial strain and hence the lower the increase in ductility. The ratio $\varepsilon_{\ell u} / \varepsilon_{f u}$ (circumferential ultimate strain/ultimate strain of the fiber) for fully wrapped circular columns (except for K3) was between 0.55 and 0.62 as shown in Table $3 \mathrm{~b}$. This may indicate that secondary effects near failure, such as stress concentrations in the FRP due to non-homogeneous deformations of the damaged concrete are significant. This may have led to a non-uniform distribution of the strain in the FRP wrapping. It should be noted that the ultimate tensile failure strain $\left(\varepsilon_{f u}\right)$ reported by the manufacturer was much higher than the mean strain value obtained in this study. The ultimate failure strain reported by the manufacturer was $0.4 \%$.

Comparing fully and partially wrapped columns with the same type and total amount of FRP (Table $3 a, b)$, less efficiency is obtained in case of partial wrapping as part of the concrete is unconfined. Furthermore, helicoidal wrapping results in a lower strength increase and axial strain compared to circular wrapping. This is due to the fact that the fibres are no longer aligned in an optimum way to restrain the lateral expansion of the concrete. The ratio $\varepsilon_{\ell u} / \varepsilon_{f u}$ obtained for the partially wrapped columns (K6 and K7) equals 0.3, which is much lower than the fully wrapped circular columns.

\subsection{Effective FRP strain coefficient}

According to the obtained test results, the mean effective FRP failure strain (circumferential failure strain, $\varepsilon_{\ell u}$ ) when reaching the ultimate state of the wrapped members is lower than the ultimate FRP 
strain $\varepsilon_{f u}=f_{f} / E_{f}$. The ratio of the circumferential strain at failure to the ultimate tensile strain of the FRP is referred to, as the effective FRP strain coefficient $\left(\beta=\varepsilon_{\ell u} / \varepsilon_{f u}\right)$. Thus, the maximum lateral confinement pressure $f_{\ell u}$ is given as:

$$
f_{\ell u}=K_{c o n f} \frac{\beta \cdot f_{f}}{E_{f}}
$$

For fully wrapped circular cross-sections $K_{\text {conf }}$ is given by

$$
K_{\text {conf }}=\frac{2 t_{f} E_{f}}{D}
$$

where $E_{f}$ is the elastic modulus of the FRP composite, $f_{f}$ is the ultimate strength of the FRP composite, $t_{f}$ is the thickness of the fiber and $D$ is the diameter of the unconfined concrete.

To quantify the effective FRP strain coefficient $(\beta)$, using the results of this study and others (Picher 1996, Watanable 1997, Mirmiran 1998, Matthys 1999, Toutanji 1999, Xiao 2000, Pessiki 2001), the coefficient $(\beta)$ was expressed as a function of the parameter $K_{\text {conf }}$, as shown in Figure 2. For the purpose of obtaining a simple design equation for the lateral confinement pressure, the value $\beta$ is set to be equal to 0.6. As shown in Figure 2 the effective FRP strain coefficient $\beta$, decreases with increasing the stiffness of the fiber. This implies that the value of $\beta$ for CFRP is lower than that for GFRP, since carbon fiber has higher stiffness than glass fiber. This is in agreement with a study conducted by Lam \& Teng (2003), which showed that $\beta$ equal to 0.583 for CFRP-confined concrete cylinders and 0.669 for GFRP-confined concrete cylinders.

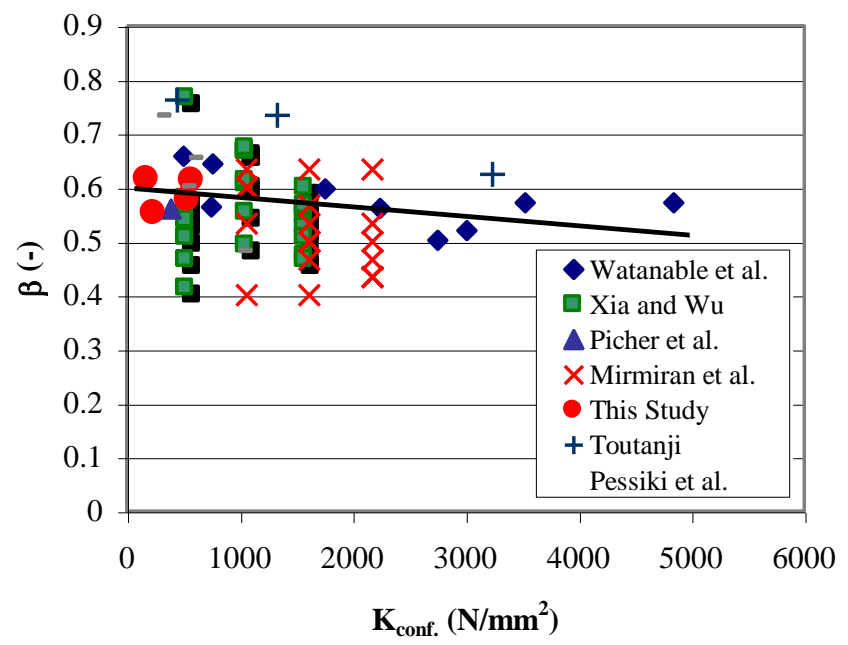

Figure 2. Effective FRP failure strain.
As $\beta$ is related to $f_{f} / E_{f}$, the strength and stiffness of the FRP should be known. Because the characterization of the tensile properties of FRP is influenced by the way of testing, the tensile strength of the FRP should be determined in accordance with ASTM D3039/D3039M or similar method using flat coupons.

\subsection{Strength models of FRP-confined concrete}

Most of the existing strength models adopted the concept of Richart et al. (1929), in which the strength at failure for concrete confined by a hydrostatic fluid pressure takes the form:

$$
f_{c c}^{\prime}=f_{c o}^{\prime}+k_{1} f_{l}
$$

where $f_{c c}^{\prime}$ is the maximum strength of the confined concrete, $f_{c o}^{\prime}$ is the maximum strength of the unconfined concrete, $f_{l}$ is the lateral confining pressure, and $k_{1}$ is a confinement effectiveness coefficient.

A number of strength models have been proposed specifically for FRP-confined concrete. These models use Eq. (3) with a modified expression for $k_{1}$. Based on regression analysis, an equation for $k_{1}$ was obtained by Toutanji (1999). When $k_{1}$ is substituted in Eq. (3), an expression to calculate the ultimate confining stress of FRP-confined concrete is obtained:

$f_{c c}^{\prime}=f_{c o}^{\prime}\left[1+3.5\left(\frac{f_{l}}{f_{c o}^{\prime}}\right)^{0.85}\right]$

where $f_{l}$

$f_{l}=\frac{2 t_{f} E_{f} \varepsilon_{l}}{D}$

Experimental data presented in this study and others (Lam \& Teng 2003) have shown that the circumferential failure strain is mostly smaller than the ultimate strain obtained from standard tensile testing of the FRP reinforcement. As shown earlier, the effective FRP strain coefficient $\left(\beta=\varepsilon_{c l u} / \varepsilon_{f u}\right)$, was expressed as a constant and equal to 0.6.

Based on this finding, Toutanji's model (1999) was modified to account for the reduction in the lateral confinement stress. Thus, the lateral confining stress becomes:

$f_{l}=\frac{2 t_{f} E_{f} \varepsilon_{c l u}}{D}$ 
$\varepsilon_{c l u}=\beta \varepsilon_{f u}$

Using a reduction factor $\beta$ of 0.6 and substituting $f_{l}$ into Eq. (1), the revised Toutanji's model to predict the ultimate axial compressive strength of FRP-confined concrete columns then can be given by the formula:

$f_{c c}^{\prime}=f_{c o}^{\prime}\left[1+2.3\left(\frac{\bar{f}_{l}}{f_{c o}^{\prime}}\right)^{0.85}\right]$

where

$\bar{f}_{l}=\frac{2 t_{f} E_{f} \varepsilon_{f u}}{D}$

where $\varepsilon_{f u}$ is the ultimate tensile strength of the FRP.

A comparison between the ultimate strength predicted by various models and the experimental ultimate strength values is shown in Figure 3. Considerable similarities were found between the different models. However, the best predictions were found in models by Miyauchi et al. (1999), Saafi et al. (1999), Samaan et al. (1999), and Toutanji Revised. As expected, the model by Mander et al. (1988) tends to overestimate the ultimate strength. This model was developed for confining concrete under triaxial compression with equal lateral effective confining stress by steel spirals or circular hoops.

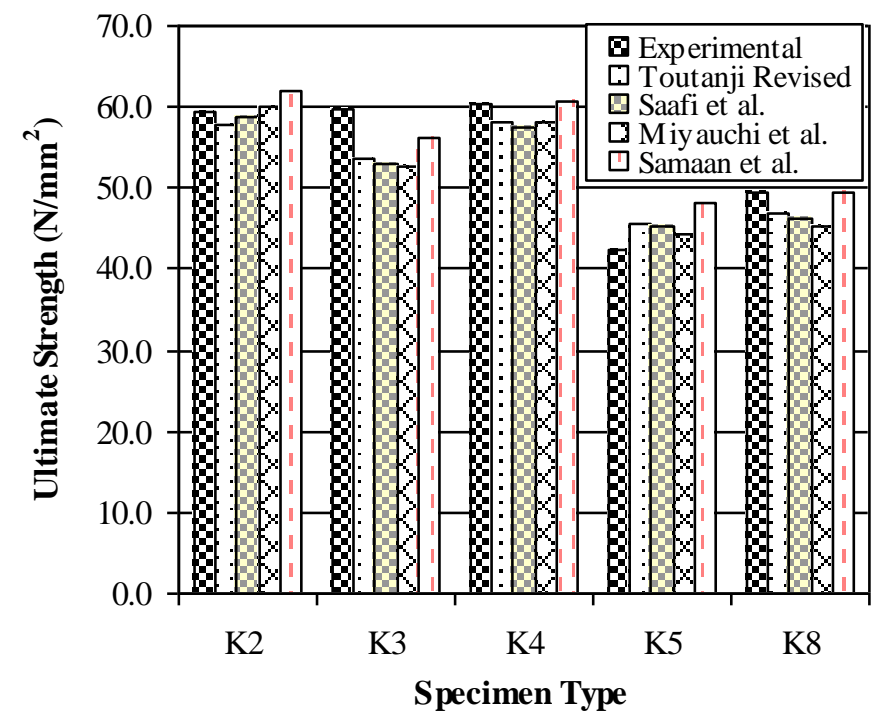

Figure 3. Comparison between the experimental values and those predicted by different models.

\section{CONCLUSIONS}

Confinement of concrete by means of FRP wrapping is an efficient technique to increase strength and ductility. The quality of execution and the wrapping configuration have a considerable influence on the effectiveness of the FRP wrapping. Beside the effectiveness (influence of partial wrapping and fibre orientation), the strength increase basically depends on the amount and tensile strength of the FRP wrapping. The increase in ductility (ultimate axial strain) is inversely proportional to the stiffness (E-modulus) of the FRP wrapping. Hence, for a given type of FRP, the higher the strength increase the lower the increase in ductility.

Due to several influencing factors, among which the local stress concentrations near failure, a reduced mean FRP failure strain is found for the wrapped specimens. To model this aspect, a reduction coefficient was introduced, referred to as the effective FRP strain coefficient $\left(\beta=\varepsilon_{\text {lu }} / \varepsilon_{\mathrm{fu}}\right)$, which is equal to 0.6. Because the characterization of the tensile properties of FRP is influenced by the way of testing, the tensile strength of the FRP should be determined in accordance with ASTM D3039/D3039M or similar method using flat coupons.

Four models, by Miyauchi et al. (1999), Saafi et al. (1999), Samaan et al. (1999), and Toutanji Revised, were found to predict the ultimate strength of FRP-confined concrete quite accurately. Results show that the predicted ultimate strengths compare well with those of experimental.

\section{ACKNOWLEDGEMENT}

The authors wish to acknowledge the financial support provided by the IWT (Institute for the Promotion of Innovation by Science and Technology in Flanders). The financial support provided by Magnel Laboratory and Ghent University to support Professor Toutanji's sabbatical leave is also greatly acknowledged. In addition, the authors would like to thank Fortius, Syncoglas, ECC, Resiplast and S\&P companies for their contributions of materials.

\section{REFERENCES}

ASTM D3039/D3039M 1995. Standard test method for tensile properties of polymer matrix composite materials. Annual book of ASTM Standards. American Society for Testing and Materials (ASTM) 15.03, Philadelphia, USA.

Lam, L. \& Teng, J.G. 2003. Stress-strain for FRP-confined concrete for design application. In K. H. Tan (ed), Proceedings of $6^{\text {th }}$ International Symposium on Fiber Reinforced Polymer Reinforcement for Concrete Structures (FRPRCS6) 2: 601-612, Singapore. 
Mander, J.B., Priestley, M.J.N. \& Park, R. 1988. Theoretical stress-strain model for confined concrete. Journal of ASCE Structural Engineering 114(8): 1804-1826.

Matthys S., Taerwe L. \& Audenaert K. 1999. Tests on axially loaded concrete columns confined by FRP sheet wrapping. In C.W. Dolan, S.H. Rizkalla, A. Nanni (eds), Proceedings of $4^{\text {th }}$ International Symposium on FRP for Reinforced Concrete Structures (FRPRCS-4): 217-228, Baltimore, USA.

Matthys, S. 2000. Structural behavior and design of concrete members strengthened with externally bonded FRP reinforcement. $\mathrm{PhD}$ Dissertation, University of Gent, Gent, Belgium.

Mirmiran, A., Shahawy, M., Samaan, M., El Echary, H., Mastrapa, J.C. \& Pico, O. 1998. Effect of column parameters on FRP-confined concrete. Journal of ASCE Composites for Construction 2(4): 175-185.

Miyauchi, K., Inoue, S., Kuroda, T. \& Kobayashi, A. 1999. Strengthening effects of concrete columns with carbon fiber sheet. Transportation Japan Concrete Institute 21: 143150.

Pessiki, S., Harries K.A., Kestner, J.T, Sause, R. \& Ricles, J.M. 2001. Axial behavior of reinforced concrete columns confined with FRP jackets. Journal of ASCE Composites for Construction 5(4): 237-245.

Picher, F., Rochette, P. \& Labossiere, P. 1996. Confinement of Concrete Cylinders with CFRP. In H. Saadatmanesh \& M. Ehsani (eds), Proceedings of 1st International Symposium on Composites for Infrastructures: 829-841, Tucson, Arizona.

Richart, F.E., Brandtzaeg, A., Brown, R.L., 1929. The Failure of Plain and Spirally Reinforced Concrete in Compression. Bulletin 190, University of Illinois Engineering Experimental Station, Champaign, Illinois, USA.

Saafi, M., Toutanji, H.A. \& Li, Z. 1999. Behavior of concrete columns confined with fiber reinforced polymer tubes. ACI Materials Journal 96(4): 500-509.

Samaan, M., Mirmiran, A. \& Shahawy, M. 1999. Model of concrete confined by fiber composites. Journal of ASCE Structural Engineering 124(9): 1025-1031.

Toutanji, H. A. 1999. Stress-strain characteristics of concrete columns externally confined with advanced fiber composite sheets. ACI Materials Journal 96(3): 397-404.

Watanable, K., Nakamura, H., Honda, Y., Toyoshima, M., Iso, M., Fujimaki, T., Kaneto, M. \& Shirai, N. 1997. Confinement effect of FRP sheet on strength and ductility of concrete cylinders under uniaxial compression. In Proceedings of $3^{\text {rd }}$ International Symposium on Non-Metallic (FRP) Reinforcement for Concrete Structures (FRPRCS-3) 1: 233240, Sapporo, Japan, JCI.

Xiao, Y. \& Wu, H. 2000. Compressive behavior of concrete confined by carbon fiber composite jackets. Journal of ASCE Materials Journal 12(2): 139-146. 